\title{
UMA ANÁLISE SEMIÓTICA DA OBRA VERBO-PICTÓRICA SONGS OF INNOCENCE AND OF EXPERIENCE, DE WILLIAM BLAKE
}

\author{
A SEMIOTIC ANALYSIS OF THE VERBO-PICTORIAL WORK SONGS OF \\ INNOCENCE AND OF EXPERIENCE, BY WILLIAM BLAKE
}

\author{
Claudia Regina Rodrigues Calado \\ UFBA - Universidade Federal da Bahia ${ }^{1}$
}

\begin{abstract}
RESUMO: William Blake foi um poeta, gravador, ilustrador e pintor do século XVIII. Desenvolveu uma técnica de impressão original chamada de Illuminated Printing (impressão iluminada), através da qual gravava poemas e desenhos em uma mesma matriz de cobre. Fez uso desse método para imprimir suas principais obras, que tinham como inconfundível característica a união de verbo e imagem. Para que pudéssemos fazer uma análise mais aprofundada de como se deu, efetivamente, o entrelaçamento entre verbal e não-verbal em Songs of innocence and of Experience (a obra que escolhemos estudar), ou ainda, para que pudéssemos observar em que medida as palavras assumiram atributos imagéticos ou vice-versa, recorremos à teoria semiótica de Charles Sanders Peirce. A investigação semiótica abrange todas as áreas do conhecimento envolvidas com as linguagens ou sistemas de significação, portanto tem por objeto de investigação todos os códigos possíveis, estabelecendo ligações entre meios semióticos diferentes. Para nossa análise, levamos em consideração, predominantemente, a relação do signo com seu objeto, pois descobrimos uma tendência à iconicidade, à indicialidade e à simbolicidade na obra em questão.
\end{abstract}

PALAVRAS-CHAVE: Songs of innocence and of Experience; William Blake; Charles Sanders Peirce; semiótica.

ABSTRACT: William Blake was a poet, engraver, illustrator and painter from the 18th century. He developed an original printing technique called Illuminated Printing, through which he engraved poems and drawings on the same copper plate. He used this method to print his main works, which were characterized by an unmistakable union of verb and image. In order to analyze more deeply how, effectively, verbal and no-verbal aspects were intertwined in Songs of Innocence and of Experience (the work we chose to study), or even, in order to observe to what extent words assumed imagistic attributes or vice-versa, we resorted to the semiotic theory by Charles Sanders Peirce. The semiotic investigation comprises all areas of knowledge involved with languages or systems of signification. Therefore, it has, as its object of investigation, all the possible codes; it establishes connections between different semiotic media. We took into consideration, in our analysis, predominantly, the relation between the sign with its object, because we found out a tendency to iconicity, indexicality and simbolicity in the referred work.

KEYWORDS: Songs of innocence and of Experience; William Blake; Charles Sanders Peirce; semiotics.

${ }^{1}$ Doutora em Letras, pela Universidade Federal da Bahia; a área de concentração é: Descrição e Análise Linguísticas. 
William Blake foi um poeta, gravador, ilustrador e pintor do século XVIII. Era um caso de doppelbegabung, denominação de Ulrich Weisstein (1982) para artistas que apresentam talentos múltiplos. Porém, diferente de outros que possuíam essa mesma característica, Blake unia poesia e gravura em um mesmo meio físico. Segundo Walter Crane (1905), quando um artista tem o dom do talento duplo, a interação entre dois meios semióticos específicos produz harmonia. Crane acreditava que Blake era um artista excepcional, que conseguia atingir "harmony between text and illustration. They become a harmonious whole, in complete relation" $\left(1905\right.$, p. 139) ${ }^{2}$.

Blake desenvolveu uma técnica de impressão original chamada de Illuminated Printing (impressão iluminada), através da qual gravava poemas e desenhos em uma mesma matriz de cobre. Fez uso desse método para imprimir suas principais obras, que tinham como inconfundível característica a união de verbo e imagem. Contudo, segundo Vaughn (1999), no trabalho iluminado de Blake, as imagens correspondentes a cada poema não eram simplesmente uma reprodução do texto verbal, mas ambas as linguagens se complementavam para formar um todo mais amplo, mais complexo. De fato, percebe-se que o poema ampliava a interpretação da imagem e vice-versa, porém, em alguns de seus últimos trabalhos, o que se lia não correspondia ao que se via, já que imagem e verbo não tinham nenhuma correlação aparentemente coerente. Não se pode dizer, portanto, que Blake ilustrava seus textos verbais, uma vez que este conceito remete ao ato de traduzir o verbal através do não verbal. Ilustrar, nas atuais concepções da atividade, significa traduzir ou ressignificar o texto de partida (ARROJO, 2002); nesse caso, a tradução é considerada independente e, embora mantenha uma relação de anterioridade com o texto fonte, é entendida como outro texto, pois é fruto de outra interpretação. No caso de Blake, o que ele faz é aliar uma linguagem à outra. Cria imagem e verbo para que funcionem juntos, como dois instrumentos dentro de uma mesma orquestra; se estiverem separados farão algum sentido, mas, se apreciados em conjunto, ampliarão e enriquecerão a interpretação da obra como um todo. Ou seja, ao se separar as duas linguagens, o poder semântico da obra fica comprometido.

Baseados nessa premissa, consideramos que, na obra iluminada de Blake, nenhuma das linguagens predomina sobre a outra. Não há uma relação de superioridade do verbo ou da imagem, ambos são igualmente importantes para uma compreensão mais ampla do todo. Porém, como já afirmamos, nem todas as suas obras possuem uma relação íntima referencial entre o verbal e o pictórico.

Escolhemos como recorte para o nosso estudo, dentre as obras que fazem parte de seus livros iluminados, Songs of Innocence and of Experience: shewing the two contrary states of the human soul (BLAKE, 2008) que, embora tenha sido publicada como um único e grande signo estético, na verdade foi escrita em duas etapas: Songs of Innocence (Canções da inocência), em 1789, e Songs of Experience (Canções da experiência), em 1794. Essa obra apresenta um alto grau de referencialidade entre os textos verbais e imagéticos; ou seja, verbo e imagem caminham juntos e se correlacionam de maneira imbricada. Nela, Blake nos mostra os dois lados da condição humana: a inocência e a experiência. Escrita no meio da grande Revolução Francesa e da grande Revolução Inglesa, a obra retrata, em sua primeira fase, uma visão mais otimista de Blake com relação ao mundo e aos homens. Ocorria, nessa época, a queda da Bastilha na França e o absolutismo monárquico era substituído por uma assembleia constituinte, que propagava um sonho de liberdade, igualdade e fraternidade (HOBSBAWN, 2009). Blake era um entusiasta dessa nova perspectiva de mudança social. Porém, com os progressos da revolução industrial na Inglaterra, cada vez mais agressiva e com os

\footnotetext{
2 “[...] harmonia entre texto e ilustração. Eles se tornam um todo harmonioso, em completa relação" (tradução nossa).
}

Disponível em: http://seer.fclar.unesp.br/casa 
revolucionários franceses assumindo posições tirânicas, Blake começava a sucumbir à descrença de que o mundo não rumava necessariamente para um futuro mais justo e promissor. Portanto a segunda fase da obra em questão dá sinais de que o pessimismo teria tomado conta de suas opiniões sobre a existência. Podemos ver, também, um autor mais sombrio, mais cético com relação à bondade, à honestidade; a inocência é então substituída pela experiência, ou seja, por um mundo corrompido pela ganância, pelo desrespeito ao próximo e pela razão. ${ }^{3}$ Os vinte e dois poemas de Songs of Innocence se contrapõem aos vinte e dois poemas de Songs of Experience.

Propomos, então, para analisar esse texto verbo-pictórico de Blake, uma abordagem que pretende verificar os fenômenos da interpretação de uma obra de arte em seu aspecto semiótico, buscando considerar seu modo de produção de sentido, ou seja, a maneira como provoca efeitos na mente de um fruidor ou receptor. Para tal, consideramos o trabalho de Charles Sanders Peirce particularmente importante. Esse cientista, lógico e filósofo, não estudou, em primeiro lugar e antes de qualquer coisa, a língua, mas tentou pensar em uma teoria geral dos signos. Então, o signo é definido como tudo aquilo que substitui ou representa alguma coisa para alguém, em certa medida e para certos efeitos, ou seja, em alguma relação ou alguma qualidade (SANTAELLA, 2000). Para Peirce (1990), um signo só é signo se exprimir ideias e se provocar, na mente daquele que o percebe, uma atitude interpretativa. Nessa perspectiva, tudo pode ser signo, desde que dele possamos deduzir uma significação que depende de nossa cultura, assim como do contexto de surgimento de um determinado sinal, já que sinal é uma outra palavra para signo.

A filosofia peirciana entende a realidade de forma pansemiótica, isto é, tudo pode ser semioticamente analisável e classificável segundo três categorias: primeiridade (aparece como primeira impressão ou sentimento que recebemos das coisas); secundidade (aparece em consequência da primeiridade; é nossa consciência do que é percebido); e terceiridade (corresponde ao nível do simbólico, da convenção, em que representamos e interpretamos o mundo).

Ampliando a noção de signo, que está situado na categoria de primeiridade, Peirce (1990) o concebeu em uma relação triádica: o signo dizendo respeito ao signo em si mesmo, o signo em uma relação com seu objeto e o signo em uma relação com seu interpretante. A saber: signo é um sinal ou uma coisa que representa algo para alguém; objeto é aquilo que é representado, manifesto ou revelado pelo signo, de alguma forma; interpretante é o efeito que o signo provoca naquele que o interpreta. Assim, Peirce (1990, p. 46) o define:

Um signo ou representamen, é aquilo que, sob certo aspecto ou modo, representa algo para alguém. Dirige-se a alguém, isto é, cria na mente dessa pessoa um signo equivalente, ou talvez, um signo mais desenvolvido [...]. O signo representa alguma coisa, seu objeto [...]. Defino um Signo como qualquer coisa que, de um lado, é assim determinada por um Objeto e, de outro, assim determina uma ideia na mente de uma pessoa, esta última determinação, que denomino o Interpretante do signo, é, desse modo, mediatamente determinada por aquele Objeto. Um signo, assim, tem uma relação triádica com seu Objeto e com seu Interpretante.

\footnotetext{
${ }^{3}$ Blake criticava ferozmente o racionalismo exacerbado da época e advogava que o homem só poderia chegar à verdade através da imaginação e da percepção pura (VAUGHN, 1999).
}

Disponível em: http://seer.fclar.unesp.br/casa 
Em outras palavras, um signo é qualquer coisa que está relacionada a uma segunda coisa (seu objeto), de tal modo a suscitar uma terceira coisa (seu interpretante ou um efeito), em relação a esse objeto representado. Um signo, em relação ao objeto a que se refere, pode ser um ícone, um índice ou um símbolo. Concentrar-nos-emos, predominantemente, nessa segunda relação da tríade, pois percebemos uma tendência à iconicidade, à indexicalidade e à simbolicidade da linguagem em Songs of Innocence and Experience, como mostraremos mais adiante.

Um ícone é estritamente uma possibilidade, ou seja, não passa de um possível ainda não realizado, anterior à geração de qualquer interpretante. Um signo só é um ícone se ele se assemelhar ao seu objeto. O ícone (SANTAELLA, 2000) mantém uma relação de analogia com o que representa; é um signo que está conectado ao seu objeto em uma relação de similaridade. Damos como exemplo a imagem pictórica, uma das modalidades de representação da obra de Blake. Ela é um ícone quando é semelhante ao objeto retratado. Segundo Santaella e Nöth (2008, p. 38):

[Partindo de um modelo triádico de signo,] [...] o signo de imagem se constitui de um significante visual, que remete a um objeto de referência ausente e evoca no observador um significado ou uma ideia ou objeto.

Porém essa semelhança icônica pode acontecer de várias outras formas, que não só visualmente: "qualquer coisa pode ser tomada como objeto de um ícone, na medida em que apresente uma qualidade semelhante àquela que o ícone exibe" (SANTAELLA, 2000, p. 44). Peirce admite que o ícone pode compreender também formas sonoras, táteis, olfativas. Em sua tese de doutoramento, Soraya Ferreira Alves (2002) chamou a atenção para a iconicidade presente em obras da autora Virginia Woolf e destacou manifestações icônicas não necessariamente visuais, mas também acústicas. Em um trecho do romance Mrs. Dalloway, de 1925, Alves (2002) destaca um momento em que o personagem Peter caminha pelas ruas de Londres ao som de badaladas de sinos; essas badaladas são iconizadas através da repetição de nomes como Nelson, Gordon e London, que produzem, ao serem pronunciados, um som parecido ao de um sino. Temos então:

There they go, thought Peter Walsh, pausing at the edge of the pavement; and all the exalted statues, Nelson, Gordon, Havelock, the black...", "They don't know the troubles of the flesh yet, he thought, as the marching boys disappeared in the direction of the Strand - all that I've been through, he thought, crossing the road, and standing under Gordon's statue, Gordon whom as a boy he had worshipped; Gordon standing lonely with one leg raised and his arms crossed - poor Gordon, he thought. And just because nobody yet knew he was in London, ..."; “...walking across Trafalgar Square in the direction of the Haymarket, came a young woman who, as she passed Gordon's statue. (WOOLF, 1996, p.38-39).

Em sua dissertação de Mestrado, Claudia Regina Rodrigues Calado (2007) também aponta outras passagens icônicas em obras de Woolf, dessa vez, no romance The Waves (1992). No trecho em que o personagem Bernard, em silêncio, observa seus amigos Louis e Neville, também sentados em silêncio, à espera de outros amigos para um almoço, Woolf associa a volubilidade do pensamento a anéis de fumaça: frágeis e transitórios. 
"Louis and Neville", Said Bernard, "both sit silent. Both are absorbed. Both feel the presence of other people as a separating wall. But if I find myself in company with other people, words at once make smoke rings - see how phrases at once begin to wreath off my lips" (WOOLF, 1992, p. 36 grifos nossos).

Pode-se notar a preponderância e a repetição insistente de consoantes explosivas, iconizando o barulho que Bernard faz ao produzir anéis de fumaça com a boca, como um fumante ao soltar baforadas em forma de anéis.

De fato, a iconicidade é uma proposta escritural muito presente na literatura, especialmente nas metáforas e nas símiles, figuras literárias muito conhecidas. Podemos observar exemplos de iconicidade na poesia de Hopkins, como aponta Augusto de Campos, que analisa o poema “God's Grandeur" (1877) e destaca características icônicas na sua construção:

The world is charged with the Grandeur of God. It will flame out, like shinning from shook foil; It gathers to a greatness, like the ooze of oil crushed. Why do men then now not reck his rod? Generations have trod, have trod, have trod; And all is seared with trade; bleared, smeared with toil; And wears man's smudge and shares man's smell: the soil Is bare now, nor can foot feel, being shod. And for all this, nature is never spent; There lives the dearest freshness deep down things; And though the last lights off the black West went. Oh, morning, at the brown brink eastward, springs Because the Holy Ghost over the bent. World broods with the warm breast and with ah! bright wings (HOPKINS apud CAMPOS, 1997, p. 19, grifos nossos).

Campos (1997) afirma que dentre os recursos que Hopkins usa, um exemplo que podemos citar de imediato é a aliteração. No último verso, há uma sequência de pares sonoros que, de acordo com o autor (1997, p. 19), é “insubstituível”. Há, nessa construção, uma iconização do som que o movimento das asas batendo produz através da repetição da letra $\mathrm{W}$ que, além de ser a letra inicial da palavra Wing (asa, em inglês), assemelha-se também ao desenho de uma asa, numa harmonia de conteúdo e forma. Logo, a disposição das cinco palavras começadas com $\mathrm{W}$, inclusive sendo a última a própria palavra asa, permite essa interpretação icônica também pela impressão visual que a forma do poema provoca no leitor, semelhante a de uma asa. Pignatari ainda aponta manifestações icônicas na poesia de Carlos Drummond de Andrade, como nesse exemplo em que a palavra vira coisa:

\author{
Um inseto cava \\ cava sem alarme \\ perfurando a terra \\ sem achar escape
}

(ANDRADE apud PIGNATARI, 2004, p. 18-19)

Como explica Pignatari, o "inseto deste poema não é a palavra inseto, mas o vocábulo cava. Pelo corte do verso e pela reduplicação, o vocábulo-inseto "cava" é que se 
move e adentra o poema como se este fosse a terra" (2004, p. 19). Nesse caso, houve uma iconização do movimento do inseto cavando a terra através do uso da palavra "cava" no final do primeiro verso e no começo do segundo. Percebe-se também uma possível alusão ao nome do poeta francês Stéphane Mallarmé ${ }^{4}$, ainda no segundo verso, em que se lê "cava sem alarme", talvez numa tentativa de homenagear aquele considerado o precursor da poesia visual.

Neste outro exemplo, Pignatari observa na poesia de Ronaldo Azeredo um exemplo de iconicidade da linguagem. Aqui, o pôr do sol é iconizado através do posicionamento da palavra "sol", que vai sumindo aos poucos, ao longo do poema:

$$
\begin{aligned}
& \text { ruaruaruasol } \\
& \text { ruaruasolrua } \\
& \text { ruasolruarua } \\
& \text { solruaruarua } \\
& \text { ruaruaruas }
\end{aligned}
$$

(AZEREDO apud PIGNATARI, 2004, p. 58)

O que Décio Pignatari chama de "iconescritura" (1987, p. 108) pode ser compreendido como escrita icônica. Ele menciona o escritor americano Edgar Allan Poe, Mallarmé e Machado de Assis, dentre outros, como exemplos de autores que utilizaram esse recurso de escrita e afirma:

[...] a partir da descoberta de Jakobson, em sua análise de The Raven $(\mathrm{O}$ Corvo) - onde raven é 'a imagem especular encarnada' de never, o corvo dizendo-se a si mesmo, ou melhor, sendo aquilo que diz - não é difícil rastrear na obra de Poe diversos casos ilustrativos de seu peculiar método anagramático, hipogramático e anafônico, mesmo ao risco de, aqui e ali, forçar um pouco a mão às regras do jogo e desde que possa ficar passavelmente claro que tal processo de transcodificação semiótica [...] rompe a chamada linearidade do discurso, na medida mesma em que é ambígua, pois que a ambiguidade do signo poético resulta de este ser um signo em profundidade - um signo que se afasta do automatismo verbal, um signo vertical, espesso, cuja espessura resulta de camadas de signos embutidos em palimpsesto, gerando simultaneidade de informação e tendendo a ou sendo um ideograma - um ícone (PIGNATARI, 1987, p. 102-103).

Lúcia Santaella, em seu livro Matrizes da Linguagem e Pensamento (2005), apresenta outros exemplos de iconicidade existentes em algumas obras de Edgar Allan Poe, como no conto "The Fall of the House of Usher", de 1839, ou "A Queda da Casa de Usher", em Português:

\footnotetext{
${ }^{4}$ (1842-1898) Mallarmé foi um poeta concreto avant la lettre e integrante do movimento simbolista. Sua obra antecipou a sintaxe visual da poesia moderna do século XX.
} 
A casa que cai está iconizada na palavra USHER, pois essa contém todos os grafemas da palavra casa (HOUSE), com exceção do grafema $(\mathrm{O})$. Ao cair a casa, por trás da abertura de sua fenda, surge uma enorme lua redonda e vermelha. No limite da sabedoria icônica, a forma redonda da lua cheia é exatamente a forma do grafema $(\mathrm{O})$ que faltava na palavra USHER para compor a palavra HOUSE (SANTAELLA, 2005, p. 329).

Ao analisarmos Songs of Innocence and of Experience percebemos, como já afirmamos, uma tendência à iconicidade, indexicalidade e simbolicidade da linguagem. Com relação à categoria do ícone, como já explicamos, este mantém uma relação de semelhança ou propriedade com um determinado objeto a que se refere. $O$ ícone é uma abstração de algo que é do nosso conhecimento e apresenta uma semelhança com o objeto representado. Não tem, portanto, conexão dinâmica alguma com o objeto que representa; simplesmente acontece que suas qualidades se assemelham às do objeto e podem excitar sensações análogas na mente do receptor devido à essa semelhança. Ao utilizar-se de iconizações dentro de seu texto verbal, Blake une verbo e imagem, uma das principais características de seus trabalhos, já que iconiza, em sua escrita, aspectos visuais de vários poemas. Nesse tipo de construção icônica, vemos que

[...] da palavra à sentença, da sentença às combinações entre sentenças, os papéis desempenhados pela iconicidade vão se acentuando e se representando sob novas facetas, compondo uma complexa e intricada sincronização entre verbo e imagem. (SANTAELLA; NÖTH, 2008, p. 65)

Concordando com Santaella, podemos afirmar que as iconizações verbais têm a capacidade de remeter a imagens, ou seja, elas podem levar à construção de imagens diversas. Percebemos o uso deste recurso em "The Shepherd", de Songs of Innocence:

How sweet is the Shepherd's sweet lot!

From the morn to the evening he strays;

He shall follow his sleep all the day,

And his tongue shall be filled with praise.

For he hears the lamb's innocent call,

And he hears the ewe's tender reply;

He is watchful while they are in peace,

For they know when their Shepherd is nigh.

Ao colocar a palavra Shepherd somente no primeiro e no último verso, Blake iconiza a proteção do pastor com suas ovelhas; estas estão cerceadas por ele, não têm como fugir de seu cerco. $\mathrm{O}$ autor está sempre recorrendo à simbolicidade em seu texto, como explicaremos mais adiante neste trabalho; e, em especial, à simbologia judaico-cristã. Como afirma Lexicon (1990, p. 155): "Em muitas culturas, Deus é o pastor do povo de Israel e Cristo é o bom pastor. O pastor tem um significado simbólico religioso, visto ser uma figura paternal vigilante e protetora".

Em "Laughing Song” (BLAKE, 2008, p. 57), de Songs of Innocence, há um convite ao riso. A natureza ri junto com os personagens do poema. O gafanhoto, que 
geralmente tem conotação negativa por estar associado a pragas, também ri. A menção de um gafanhoto em um cenário de riso e alegria é paradoxal, já que este inseto seria geralmente relacionado às pragas bíblicas. Lê-se:

When the Green Woods laugh with the voice of joy

And the dimpling stream runs laughing by,

When the air does laugh with our merry wit,

And the green hill laughs with the noise of it.

When the meadows laugh with lively green

And the grasshopper laughs in the merry scene,

When Mary and Susan and Emily,

With their sweet round mouths sing $\mathrm{Ha}, \mathrm{Ha}, \mathrm{He}$.

When the painted birds laugh in the shade

Where our table with cherries and nuts is spread

Come live \& be merry and join with me,

To sing the sweet chorus of Ha, Ha, He.

Podemos dizer que Blake iconiza os pulos do gafanhoto risonho, ao longo do poema, através da repetição insistente da palavra laugh. É possível mesmo visualizar o gafanhoto como que pulando nos versos e marcando presença em um contexto que, simbolicamente, não seria o seu.

Em "The Tyger", de Songs of Experience, por exemplo, temos o uso da letra "Y" no título, ao invés do uso convencional da letra "I", como uma iconização da cauda do tigre, que tem forma similar. Blake atribui, assim, um caráter imagético, plástico, à letra, ao verbo, já que o formato do "Y" é bastante parecido com o da cauda do animal, enaltecido durante todo o poema por causa de sua beleza e ferocidade, aspectos que, embora opostos, fazem parte de sua natureza. ${ }^{5} \mathrm{O}$ autor, muitas vezes, foge à escrita convencional em seus poemas em detrimento de construções de cunho icônico, em que uma letra trocada, omitida ou duplicada propositalmente possa acrescentar certas impressões à interpretação do poema.

Tyger Tyger, burning bright,

In the forests of the night;

What immortal hand or eye,

Could frame thy fearful symmetry

In what distant deeps or skies.

Burnt the fire of thine eyes!

On what wings dare he aspire?

What the hand, dare seize the fire!

And what shoulder, \& what art.

Could twist the sinews of thy heart?

\footnotetext{
${ }^{5}$ As palavras são genuinamente simbólicas, mas, muitas vezes, a maneira como são escritas corresponde a seu aspecto icônico, que pode até funcionar por similaridade em relação ao seu referente, como ocorre com palavras do tipo olho, por exemplo, em que se tem uma iconização dos próprios olhos através da escrita o-o.
} 
CASA, Vol.11 n.1, julho de 2013

And when thy heart began to beat,

What dread hand! \& what dread feet!

What the hammer! what the chain, In what furnace was thy brain What the anvil, what dread grasp,

Dare its deadly terrors clasp!

When the stars threw down their spear And water'd heaven with their tears:

Did he smile his work to see

Did he who made the Lamb make thee!

Tyger Tyger burning bright, In the forests of the night:

What immortal hand or eye,

Dare frame thy fearful symmetry.

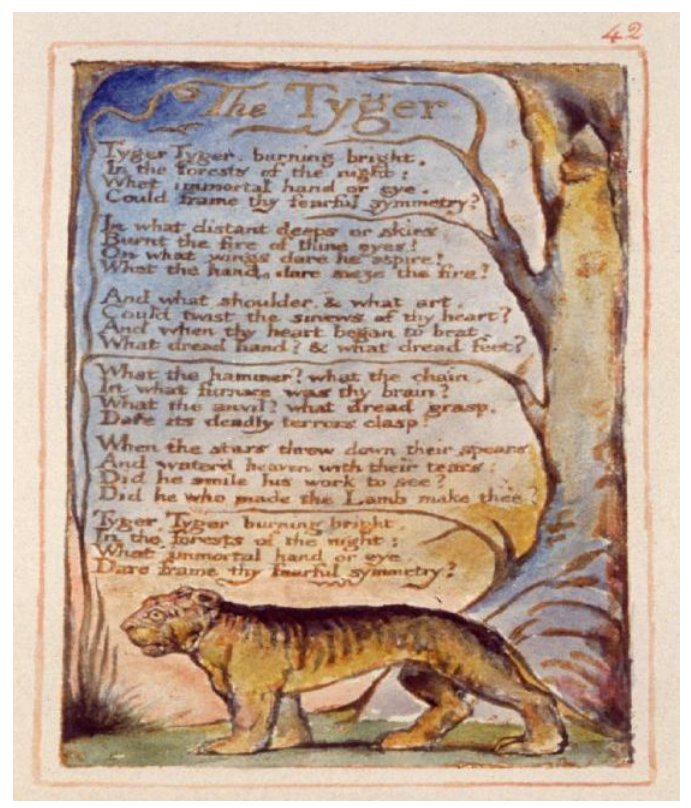

Fig. 01 - Matriz de "The Tyger" Fonte: Blake, 2008, p. 84

Vemos como, através da iconicidade, Blake aproxima verbo e imagem. Blake iconiza também a própria simetria do animal através do uso de letras dobradas: a simetria contida na própria palavra SYMMETRY, onde vemos duas letras Y e duas letras M; as patas do tigre são simétricas, os olhos também e a palavra IMMORTAL tem um duplo M, que sugere simetria. Logo, a simetria pode estar associada às formas perfeitas do tigre, a suas listras, seu compasso, seus olhos, suas patas. Vemos uma abundância de duas palavras começadas com a mesma letra, num mesmo verso; e também há palavras que têm letras dobradas. Naturalmente, tudo isso parece estar iconizando a simetria do animal. Augusto de Campos propôs uma tradução para o poema intitulada "O Tygre" (CAMPOS, 1986, p. 221): 
CASA, Vol.11 n.1, julho de 2013

Tygre! Tygre! Brilho, brasa que a furna noturna abrasa, que olho ou mão armaria tua feroz symmetrya?

Em que céu se foi forjar o fogo do teu olhar?

Em que asas veio a chamma?

Que mão colheu esta flamma?

Que força fez retorcer

em nervos todo o teu ser?

E o som do teu coração

de aço, que cor, que ação?

Teu cérebro, quem o malha?

Que martelo? Que fornalha

o moldou? Que mão, que garra

seu terror mortal amarra?

Quando as lanças das estrelas

cortaram os céus, ao vê-las,

quem as fez sorriu talvez?

Quem fez a ovelha te fez?

Tygre! Tygre! Brilho, brasa que a furna noturna abrasa, que olho ou mão armaria tua feroz symmetrya?

Nota-se que o tradutor optou por manter o nome do animal com Y, na versão em português, demonstrando uma atenção especial a essa construção. Também, escolhe uma grafia para a palavra "simetria" muito semelhante à da língua inglesa. Além disso, dobra letras deliberadamente, nas palavras "chama" e "flama". Talvez Campos tenha observado essas mesmas manifestações icônicas e tenha resolvido trazê-las para a língua de chegada, já que sua proposta, enquanto tradutor, seria recriar o texto de partida, mas respeitando suas sutilezas e peculiaridades. Augusto de Campos e seu irmão Haroldo de Campos levaram a prática da tradução criativa às últimas consequências. O que o primeiro chama de in-tradução o segundo chama de transcriação. De qualquer maneira, ambos os neologismos nomeiam um tipo de tradução que ultrapassa os limites do significado e se propõe a fazer funcionar o próprio processo de significação do texto de partida em uma outra língua. Essa proposta retoma criativamente o "modo de intencionar" do original e o recria de modo artístico, através das sutilezas que a nova forma em português possa sugerir. Atualmente parece haver um consenso de que o ato de tradução exige, muitas vezes, do tradutor uma prática criativa e crítica capaz de recriar o texto original, buscando contemplar efeitos estéticos do texto em questão. Nesse sentido, a tradução para Augusto de Campos (1986) propõe um olhar crítico sobre o texto estrangeiro para que sua versão para a língua materna supere a ideia de cópia e venha a se tornar um produto que traga algo de acréscimo ao texto que o antecedeu. Tradução 
para ele é, portanto, um modo de conversar com os poetas que ele mais admira: "A minha maneira de amá-los é traduzi-los" (CAMPOS, 1988, p. 07).

No poema "The Lilly", de Songs of Experience, temos, mais uma vez, uma grafia que foge da convenção, já que originariamente, a palavra lily (lírio) é escrita com um "L" só.

\section{The modest Rose puts forth a thorn: \\ The humble Sheep, a threatening horn: \\ While the Lilly white, shall in Love delight, \\ Nor a thorn nor a threat stain her beauty bright.}

Parece-nos que Blake iconiza, através do paralelismo do duplo "L" em lilly a própria duplicidade inerente ao conteúdo do poema. A Rosa aqui é portadora de modéstia, que, para Blake, seria um atributo negativo, pois representaria a opressão e a submissão aos dogmas religiosos, típicos do mundo da Experiência. O Lírio, por sua vez, é portador do amor e da beleza, sem a proteção dos espinhos, portanto, sem defesa, fato que o aproximaria do mundo da Inocência. Segundo Lexicon (1990, p. 125), "O lírio branco é um antigo símbolo da luz. É considerado, na iconografia cristã, um símbolo da pureza, da inocência e da virgindade". Temos, então, uma iconização dos opostos representados pela Rosa e pelo Lírio. A primeira assume aspectos da Experiência, o segundo, aspectos da Inocência, mas que, como nos "Ls" da palavra lilly, convivem e fazem parte de uma mesma condição existencial, compartilhando um mesmo espaço.

Como já afirmamos, há muitos casos de iconizações acústicas dentro do universo verbal. Na primeira matriz de "A Cradle Song” (fig. 01), de Songs of Innocence, a mãe referida no poema tenta fazer seu bebê dormir. Há uma repetição abundante das palavras sleep e sweet, provavelmente iconizando o som que a mãe estaria produzindo, ao fazer a criança dormir ou o próprio som produzido pelo berço, que está sendo embalado. Na segunda matriz do poema (fig. 02), onde estão contidas as duas últimas estrofes, a criança já está adormecida; então, essas duas palavras não aparecem mais.

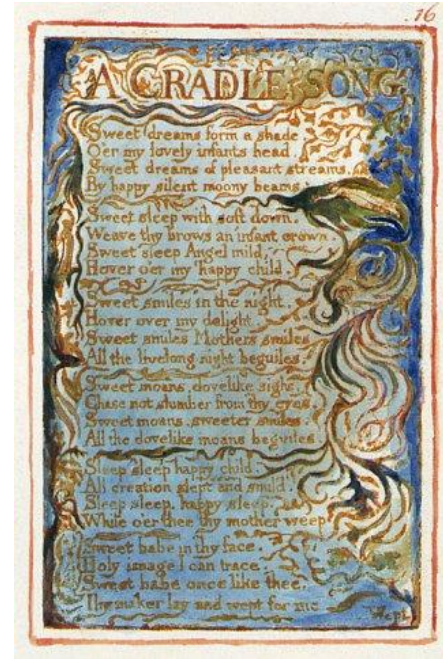

Fig. 02 - Primeira matriz de "A Cradle Song" Fonte: BLAKE, 2008, p.58

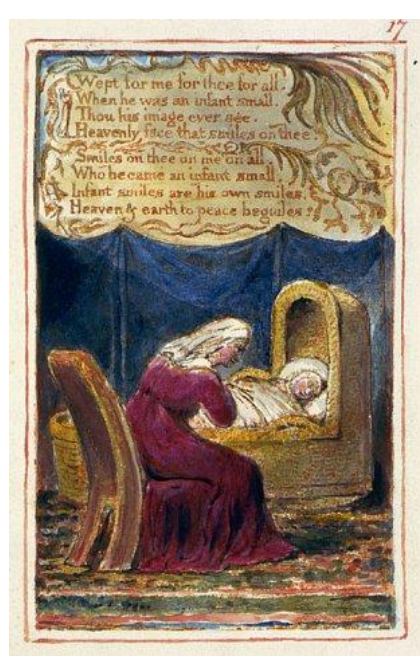

Fig. 03 - Segunda matriz de "A Cradle Song" Fonte: BLAKE, 2008, p.59 
CASA, Vol.11 n.1, julho de 2013

Sweet dreams, form a shade

O'er my lovely infant's head:

Sweet dreams of pleasant streams;

By happy, silent, moony beams.

Sweet sleep, with soft down

Weave thy brows an infant crown.

Sweet sleep, Angel mild,

Hover o'er my happy child.

Sweet smiles, in the night

Hover over my delight;

Sweet smiles, mother's smiles,

All the livelong night beguiles.

Sweet moans, dovelike sighs,

Chase not slumber from thy eyes.

Sweet moans, sweeter smiles,

All the dovelike moans beguiles.

Sleep, sleep, happy child,

All creation slept and smil'd;

Sleep, sleep, happy sleep,

While o'er thee thy mother weep.

Sweet babe, in thy face

Holy image I can trace.

Sweet babe, once like thee,

Thy maker lay and wept for me,

Wept for me, for thee, for all,

When he was an infant small.

Thou his image ever see,

Heavenly face that smiles on thee,

Smiles on thee, on me, on all;

Who became an infant small.

Infant smiles are his own smiles;

Heaven \& earth to peace beguiles.

Vimos alguns exemplos de como agem os ícones, que "para funcionarem como signos dependem de hipotéticas relações de similaridade" (SANTAELLA, 2000, p. 121). De maneira diferente, os índices correspondem à classe dos signos que mantêm uma relação causal ou de contiguidade física com o objeto que representam. São exemplos de índices: uma batida na porta como sinal de uma visita, um furo de bala na parede, os sintomas de uma 
doença, dentre outros; ou seja, onde houver uma ligação dinâmica, uma conexão física entre o signo e o seu objeto, podemos afirmar que o índice está capacitado a agir como tal.

Ao índice, muito mais do que a qualquer outro tipo de signo, cabe com justeza a denominação de veículo. De fato, ele funciona como um veículo de transporte, alertando e conduzindo o receptor diretamente para seu objeto (SANTAELLA, 2000, p. 123).

Nesse caso, podemos dizer que ao gravar (gesto mecânico) palavra e imagem, de maneira inseparável, sobre a matriz de cobre, construindo um macro texto costurado pelas duas linguagens - em que galhos de árvores separam estrofes ou destacam títulos, ou ainda, ramos, folhagens e chamas unem-se a letras, bem como a animais, figuras humanas e figuras divinas que parecem deitar-se sobre os versos - Blake indiciava sua intenção de unir textos verbais e imagéticos. Em outras palavras, podemos dizer, então, que a ação da mão de Blake gravada e registrada sobre a matriz de cobre (objeto) funcionaria como um índice de sua intenção de unir verbo e imagem (signo). Existe, entre os dois elementos, uma relação de conexão física: "Há, nesses gestos da mão, gastos de energia (corporal e intelectual) [...] a energia gasta pelos escritores sobre suas folhas de rascunho" (GRÉSILLON, 2007, p. 34-35).

É preciso, talvez, deter-se um instante nessa percepção física da escritura, muitas vezes invocada, mas raramente analisada nos seus efeitos. Ela marca a divisão, na criação do texto, entre a abstração das operações mentais e a realidade do trabalho da mão. Ao simbolismo do alfabeto ela acrescenta uma dimensão gestual e testemunha a presença, na escritura, de um sujeito escrevendo (HAY, 2007, p. 167).

$\mathrm{Na}$ matriz de abertura de Songs of Innocence (fig. 03), podemos perceber a presença de figuras humanas e angelicais, de crianças, de frutas e de pássaros misturando-se e interagindo harmoniosamente com as letras que formam o título da obra; estas parecem servir de abrigo, encosto ou moradia para seres que descansam, brincam ou se divertem. A mesma configuração acontece também em outras matrizes, como é o caso de "Nurses Song" (fig. 04), de Songs of Innocence. 
CASA, Vol.11 n.1, julho de 2013

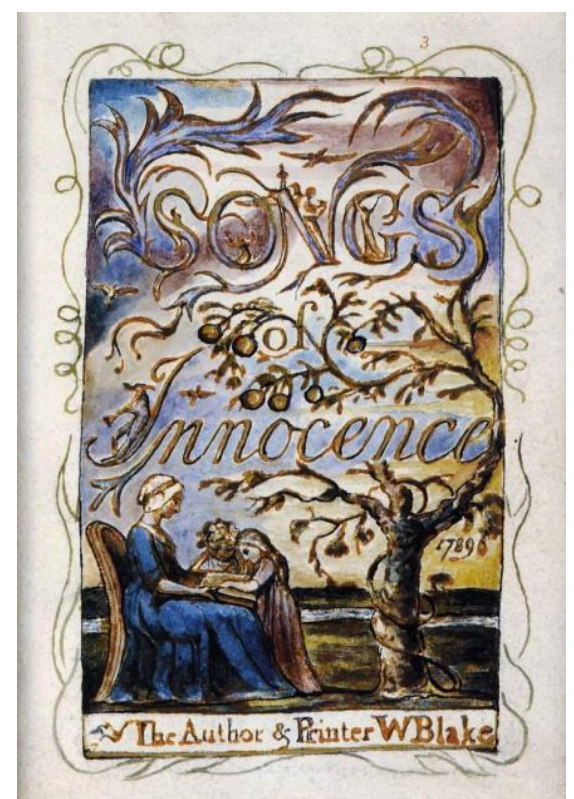

Fig. 04 - Matriz da capa de Songs of Innocence

Fonte: BLAKE, 2008, p. 45

Chamamos a atenção ainda para a presença de um flautista, personagem recorrente nas "Canções", que lembra a figura de Pan, deus dos bosques, dos pastores e dos rebanhos na mitologia grega. ${ }^{6}$ Aqui, ele poderia ser considerado uma espécie de bardo, aquele que é o encarregado de transmitir as histórias e lendas de forma oral. Ele é o personagem inicial da "Inocência", o que abre o primeiro poema da série de maneira jubilosa e exultante. O que gostaríamos de destacar é o fato de que ele toca sua flauta recostado à letra "I" de Innocence, indiciando uma das grandes e mais importantes características da obra: o entrelaçamento entre imagem pictórica e verbo.

Percebemos claramente como Blake construiu imagem e verbo de maneira inextricável, tornando impossível para seu leitor dissociar ambas as linguagens; esta é uma característica presente em todos os poemas das "Canções". Em "Nurses Song" (fig. 04), de Songs of Experience, ramos e folhas de videiras confundem-se com o próprio texto verbal. O "S" da palavra Song (no título) está ligado ao desenho de uma flor. A palavra arise, que aparece no segundo verso da segunda estrofe, está unida a um galho que se expande pela matriz.

${ }^{6}$ Disponível em: <http://pt.scribd.com/doc/2087573/Dicionario-de-Mitologia-Grega-e-Romana> Acessado em 06 de Jan. de 2012. 
CASA, Vol.11 n.1, julho de 2013

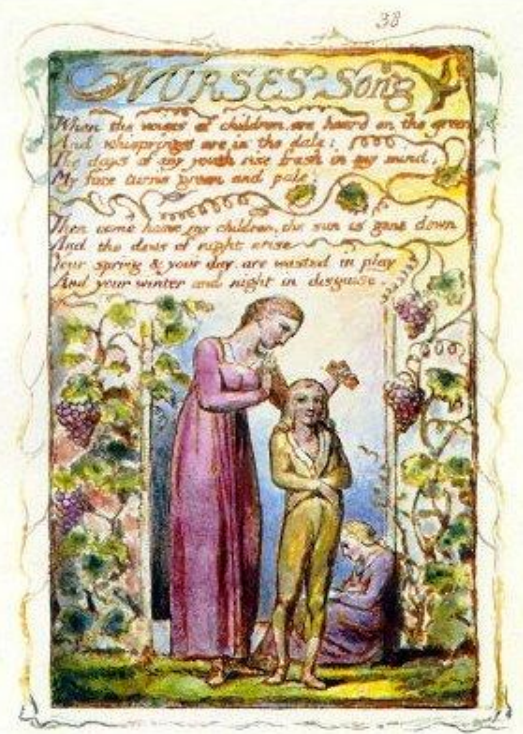

Fig. 05 - Matriz de "Nurses Song"

Fonte: BLAKE, 2008, p. 80

1

Em "The Tyger" (fig. 01), a planta do lado esquerdo inferior se junta ao "T" do título e algumas estrofes são separadas pelos galhos da árvore. Galhos de árvore também separam as estrofes em "A Poison Tree" (fig. 06) e em "The Lamb" (fig. 07), que ainda tem seu texto verbal contornado por vários ramos. Em "The Chimney Sweeper" (fig. 08), a fumaça cinza que sai da chaminé serve como pano de fundo para o texto verbal e mistura-se com o título do poema.

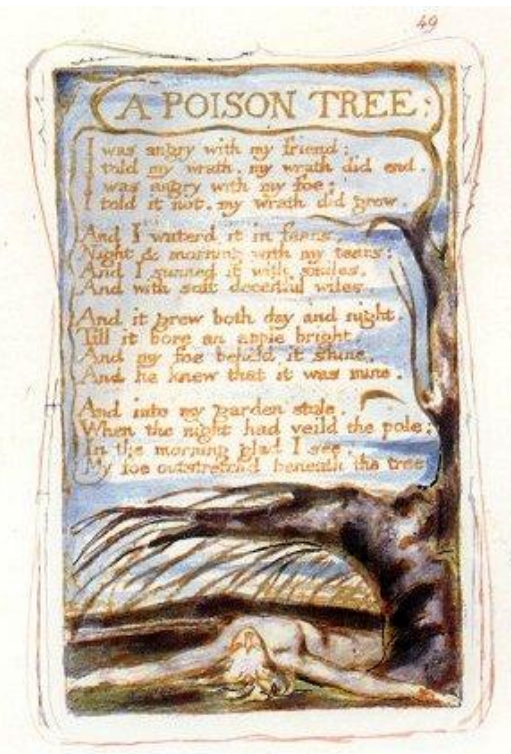

Fig. 06 - Matriz de "A Poison Tree" Fonte: BLAKE, 2008, p. 91

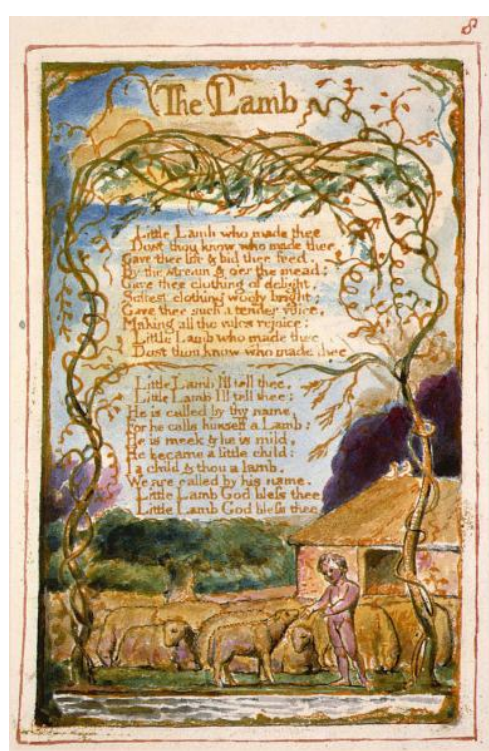

Fig. 07 - Matriz de "The Lamb" Fonte: BLAKE, 2008, p. 50 


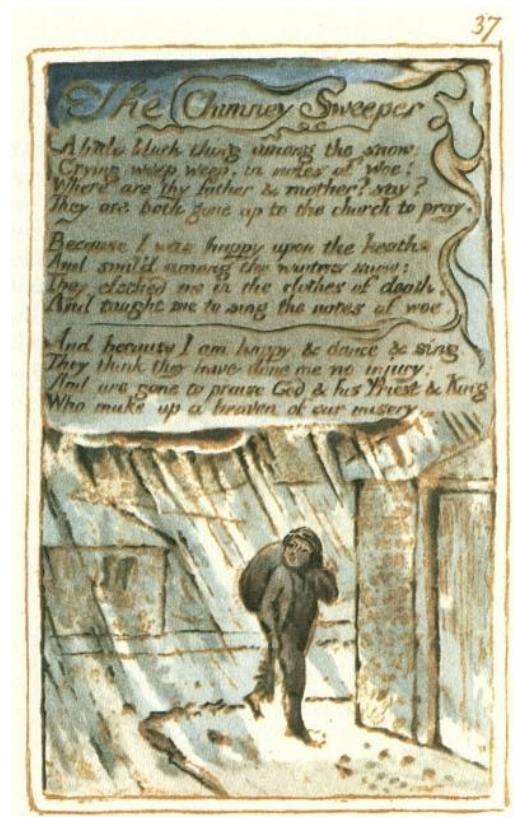

Fig. 08 - Matriz de "The Chimney Sweeper" Fonte BLAKE, 2008, p. 79

Como podemos constatar, há, nessas construções, a ação da mão de Blake gravada sobre o cobre indiciando a sua intenção de unir textos verbais e textos pictóricos. Ora, se o índice é um signo que se refere ao objeto denotado em virtude de ser realmente afetado por esse objeto, podemos afirmar então que ele está bastante presente nesta obra, pois Blake construiu Songs of Innocence and of Experience de próprio punho, unindo verbo e imagem em uma mesma matriz, de maneira que as duas linguagens ficassem entrelaçadas, numa ação mecânica que indicia a sua intenção. Daí advogarmos que a questão da junção dos textos verbais e dos textos imagéticos seja uma marca de grande destaque dentro de sua dialética da união dos contrários, já que, idiossincraticamente, ele era poeta e pintor.

Quanto ao símbolo (que também está presente em Blake), este correspondente à classe dos signos que mantém uma relação de convenção com seu referente; enquanto o ícone sugere seu objeto através de associações por semelhança e o índice através de uma conexão de fato, existencial, o símbolo, por sua vez, o representa através de uma lei (JOLY, 1996). É no interpretante que se realiza, por meio de uma regra associativa e convencional, uma associação de ideias na mente do intérprete, associação esta que estabelece certa conexão entre o signo e seu objeto. O símbolo se constitui como tal apenas através do interpretante, do efeito causado que, neste caso, é uma interpretação do objeto representado. Blake abusa de motivações simbólicas, especialmente religiosas, em sua obra como um todo. Ao escrever o poema "The Lamb" 7 (O Cordeiro), de Songs of Innocence, ele refere-se claramente ao cordeiro de Deus, Jesus Cristo, em contraposição ao tigre, de Songs of Exeperience. O

\footnotetext{
7 Cordeirinho, quem te fez?/Pois tu sabes quem te fez?/Deu-te a vida e deu-te pasto,/Ribeirinho e largo prado;/Deu-te roupa de delícia,/Lã macia sem malícia;/\& deu-te esta voz tão terna,/Alegrando toda a terra:/Cordeirinho, quem te fez?/Pois tu sabes quem te fez?/Cordeirinho, vou dizer-te,/Cordeirinho, vou dizerte;/É chamado por teu nome,/Pra si mesmo dá teu nome:/Ele é meigo \& moderado,/De menino ele é chamado:/Eu menino \& tu cordeiro,/Temos hoje o nome dele./Cordeirinho, Deus te crie./Cordeirinho, Deus te crie. Tradução de Mário Alves Coutinho e Leonardo Gonçalves (In: BLAKE, 2005, p. 33).
} 
primeiro representaria o bem, a gentileza, enquanto o segundo representaria o mal e a crueldade. Como afirma Alves (2001, p. 11):

O modo de ilustração utilizado por William Blake está intimamente conectado ao tipo de literatura simbólica criada por ele, e também à sua poética - na qual a imaginação era considerada a principal faculdade mental no ato criativo, enquanto aos ditames da razão era conferida a categoria de algo que perturba a criação com seus princípios e regras. Isso valia não só para a relação do artista com sua obra, mas também para a fruição da obra de arte pelo espectador. Além de conter esse caráter altamente simbólico referido acima, seus livros apresentam um outro agravante à compreensão do leitor que se aventura por suas páginas: o sistema simbólico que ali se apresenta não segue uma tradição estabelecida, como a obra de Dante, por exemplo. Podemos identificar referências à Bíblia, à textos místicos como Böhme ou Swedenborg e, principalmente à outras obras literárias, como as de Milton. No entanto, não se contentando com esse panorama, Blake foi além: iniciou ele mesmo a criação de um universo simbólico próprio, com sua cosmogonia e mitologia

Portanto, não trataremos especificamente dos aspectos simbólicos de Songs of Innocence and of Experience, em especial, porque este trabalho não comporta sua complicada mitologia. Discorreremos somente sobre as referências simbólicas de cunho basicamente judaico-cristão nela presentes, pois para investigarmos sua simbologia de maneira mais aprofundada, necessitaríamos fazer um estudo à parte, dada sua complexidade. Para Northrop Frye (1969), os símbolos usados por Blake só podem ser entendidos de maneira mais ampla, a partir da relação que eles estabelecem com sua obra inteira. Ou seja, para podermos construir significados mais aprofundados dos símbolos que se encontram em Songs of Innocence and of Experience, teríamos que relacioná-los com a simbologia de sua obra como um todo, tarefa que não se configuraria como objetivo deste trabalho. Porém, é importante salientar que nenhum signo pode ser descrito como tendo somente características de ícone, índice ou símbolo. Esses três tipos de signo se apresentam de maneira complementar: o símbolo contém o índice e o ícone; já o índice, contém também o ícone; porém, o ícone, por ser tão fugaz, já que provoca sensações na mente do receptor em um lampejo, seria indivisível, por isso, uma mônada. O que pode haver é que, em determinadas situações, haja uma predominância ou destaque-se uma manifestação de algumas dessas categorias. Em nosso estudo, optamos por privilegiar a iconicidade e a indicialidade, que pudemos perceber na obra de Blake:

Peirce afirmou que, após classificar os signos, na sua tipologia fundamental, ele passava a examinar as diferentes eficiências e ineficiências de cada um desses tipos. Nenhum tipo de signo é autossuficiente. Tais como as categorias fenomenológicas, os signos são mútuo-complementares. Todo signo atual (mesmo um pensamento, quando se trata de um pensamento atualizado numa mente específica) aparece numa mistura de caracteres. Não há nenhuma linguagem que possa se expressar em nível puramente simbólico, indicial ou icônico (SANTAELLA, 2000, p. 27).

Desse modo, a teoria semiótica peirceana nos pareceu particularmente útil, pois nos permitiu penetrar na tessitura de Songs of Innocence and of Experience, dando-nos a possibilidade de tentar compreender os mais diversos procedimentos e recursos empregados 
por Blake para a construção do entrelaçamento entre verbo e imagem na sua obra. A partir do que foi percebido, consideramos o trabalho desse artista como único, pois acreditamos que ele buscava uma completa e absoluta interação entre verbo e imagem. Não cremos que os textos pictóricos que compôs sejam repetições do conteúdo dos textos verbais, mas, juntamente com estes últimos, a própria essência do seu corpo poético. Roman Jakobson propôs um estudo do poema "Infant Sorrow", de Canções da Experiência e destacou a "surpreendente simetria" existente em seus versos, pausas e aliterações (JAKOBSON, 1990, p. 132), o que indica que Blake se empenhava, de maneira prodigiosa, na feitura de seus textos. Porém, não concordamos com Jakobson quando este afirmou que os textos verbais de Blake deveriam ser lidos com suas ilustrações respectivas. Acreditamos que não se pode pensar, neste caso, os textos imagéticos como ilustrações dos textos verbais, pois estaríamos admitindo que estes últimos seriam os pontos de partida para a construção dos textos pictóricos. Pensamos que a arte de Blake é composta e deve ser vista como uma unidade. É possível que o artista tenha assumido uma das duas linguagens como referência para a produção da outra, mas não há como afirmar qual delas ou se isso realmente aconteceu sem um estudo aprofundado de seu processo de criação.

Muito foi feito antes e depois de Blake em termos de união de verbo e imagem, mas pensamos que nada se compara, em originalidade, às suas obras. Como vimos, o que Blake preconizava, especialmente em Canções da Inocência e da Experiência, era a questão da união dos contrários como partes de um todo para que o homem pudesse ver tudo de maneira infinita, já que as portas de sua percepção, desse modo, estariam abertas. Da mesma maneira, através de sua Impressão Iluminada, Blake também relacionava duas artes, poesia e pintura, consideradas por muitos estudiosos como opostas ou rivais; porém, são vistas por ele como dois elementos diferentes que, juntos, formariam uma só composição. Assim, ele desenvolveu algo particular e explorou essa correspondência de maneira única: a imagem poderia acrescentar algo à interpretação do verbo (ou até mesmo mudá-la) e vice-versa. Uma era a metade da outra; duas vozes cantando em dueto. Essa associação está bem clara nas "Canções". Gravação e poema podem ser vistos como dois personagens, cada um representando um papel dentro de cada canção; ou ainda, como instrumentos de uma orquestra em que nenhuma das partes tem uma posição privilegiada sobre a outra, ou de destaque. Funcionam harmonicamente como complementos necessários a uma interpretação ou apreciação mais ampla e complexa de cada uma das canções.

\section{REFERÊNCIAS}

ALVES, A. L. Oposição é verdadeira amizade: imagem poética e pictórica no livro $\mathrm{O}$ Matrimônio do Céu e do Inferno de William Blake. 2001. Dissertação de Mestrado. Universidade Estadual de Campinas, Campinas.

ALVES, S. F. A Escritura Semiótico-Diagramática de Virginia Woolf: interfaces Comunicativas. 2002. Tese de Doutorado. PUC, São Paulo.

ARROJO, R. Oficina de tradução: a teoria na prática. 4. ed. São Paulo: Ática, 2002.

BLAKE, W. Canções da inocência e da experiência. Trad., prefácio e notas de Mário Alves Coutinho e Leonardo Gonçalves. Belo Horizonte: Crisálida, 2005.

The Complete Illuminated Books. Introdução de David Bindman. Londres: Thames and Hudson, 2008.

CALADO, C. R. R. A tradução da iconicidade em The Waves, de Virginia Woolf. 2007. Dissertação de Mestrado. Universidade Estadual do Ceará, Fortaleza. 
CAMPOS, A. de. Viva vaia: poesia, 1949-1979. São Paulo: 1986.

Verso, reverso, controverso. São Paulo: Perspectiva, 1988.

Hopkins: A beleza difícil. São Paulo: Perspectiva, 1997.

CRANE, W. Of the decorative illustration of books old and new. London: George Bell \& Sons, 1905.

FRYE, N. Fearful Symmetry: a study of William Blake. Princeton: Princeton University Press, 1969.

GRÉSILLON, A. Elementos de Crítica Genética: ler os manuscritos modernos. Trad. Cristina de Campos Velho Birck et al. Porto Alegre: Editora da UFRGS, 2007.

HAY, L. A literatura dos escritores: questões de crítica genética. Tradução de Cleonice Paes Barreto Mourão. Belo Horizonte: Editora UFMG, 2007.

HOBSBAWN, E. A Era das revoluções: Europa 1789-1848. Trad. Maria Tereza Lopes Teixeira e Marcos Penchel. Rio de Janeiro: Paz e Terra, 2009.

JAKOBSON, R. Poética em Ação. São Paulo: Perspectiva, 1990.

JOLY, M. Introdução à análise da imagem. Trad. Marina Appenzeller. Campinas: Papirus, 1996.

LEXICON, H. Dicionário de símbolos. Trad. Erlon José Paschoal. São Paulo: Cultrix, 1990.

PEIRCE, C. S. Semiótica. Trad. José Teixeira Coelho Neto. São Paulo: Perspectiva, 1990.

PIGNATARI, D. Poesia pois é poesia. Campinas: Editora da UNICAMP, 2004.

SANTAELLA, L. Matrizes da linguagem e do pensamento: sonora, visual, verbal. São Paulo: Iluminuras, 2005.

A teoria geral dos signos: como as linguagens significam as coisas. São Paulo:

Editora Pioneira, 2000.

\& NÖTH, W. Imagem: cognição, semiótica e mídia. São Paulo: Iluminuras, 2008.

VAUGHAN, W. William Blake. New Jersey: Princeton University Press, 1999.

WEISSTEIN, U. Literature and the visual arts. In: BARRICELLI, Jean-Pierre; GIBALDI, Joseph (eds.). Interrelations of literature. New York: MLA, 1982.

WOOLF, V. The Waves. London. Penguin Books,1992.

. Mrs. Dalloway. Hertfordshire: Wordsworth Editions Limited, 1996.

Recebido em: 17.03 .13

Aprovado em: 20.05.13 